\title{
Sustainable Development at Higher Education Institutions in Germany: Advances, Challenges, Examples
}

\author{
Claudia Thea Schmitt ${ }^{1}$, Alexander Bassen ${ }^{1}$, Georg Müller-Christ ${ }^{2}$ \\ ${ }^{1}$ Center for a Sustainable University (KNU), Universität Hamburg, Germany. ${ }^{2}$ Department \\ of Economics, Universität Bremen, Germany
}

\begin{abstract}
In this paper, Sustainable Development at Higher Education Institutions is introduced as a field of research and application. An interdisciplinary German collaboration on Sustainable Development at Higher Education Institutions - $\mathrm{HOCH}^{N}$ - serves as case example of how this topic is addressed on a national level. Results and advances of the $\mathrm{HOCH}^{N}$ collaboration are summarized. Moreover, challenges of implementing sustainability-related organizational development at universities are discussed. Focusing on Education for Sustainable Development at universities, three different methodologies are outlined that exceed conventional approaches in tertiary education: Lego ${ }^{\circledR}$ Serious Play ${ }^{\circledR}$ methodology, constellation techniques, and a coaching program on the "Five Minds for the Future". They illustrate different ways of addressing issues of Education for Sustainable Development and skills and habits respectively that are crucial for achieving the global Sustainable Development Goals of the UN.
\end{abstract}

Keywords: Sustainable Development; Education for Sustainable Development; $\mathrm{HOCH}^{N}$. 


\section{Sustainable Development - General Framework}

The topic of Sustainable Development (SD) has a long and yet diverse history in the Anthropocene. Although the term sustainability was shaped within a forestry context in the early 1700s, a rather complex notion of care and responsibility for nature and social entities can even be tracked far back to early indigenous people (Hendry, 2014). Of course, societies, values, and knowledge have evolved ever since and thus have contexts as well as particular meanings assigned to the notion of SD. Today, as mankind is becoming increasingly aware of planetary boundaries and global societal challenges, SD is claimed and required on a large scale (Steffen et al., 2015). Global political institutions try to raise attention and action for SD and Education for Sustainable Development (ESD) respectively. UNESCO's roadmap for implementation of the Global Action Programme on ESD (2014) and especially the Sustainable Development Goals (SDGs) adopted by the UN in September 2015 emphasize the relevance and urgency of transformation towards a global, integrated view of "planet, people and prosperity". It is against this backdrop that a growing number of universities all over the world intensifies efforts to incorporate (E)SD measures into their core processes (cf. Leal Filho, Shiel \& Paço, 2016). Therefore, general advances in Higher Education and Higher Education Institutions (HEIs) are substantially linked to progress in (E)SD in particular. International as well as national partnerships aim at strengthening joint endeavors for qualified (E)SD and its evaluation. Objectives of this paper therefore are: a) to provide an example for networking on SD by introducing a research collaboration called "Sustainability at Higher Education Institutions: develop, network, report” - $\mathrm{HOCH}^{\mathrm{N}}$; b) to briefly discuss advances and challenges within the applied field of SD at universities in Germany; c) to illustrate methods of ESD used within the $\mathrm{HOCH}^{\mathrm{N}}$ context.

\section{Sustainable Development at Higher Education Institutions - The HOCH collaboration}

Initiated by the Center for a Sustainable University (KNU) of Universität Hamburg, a research collaboration on implementing SD at German HEIs was started in 2016: $\mathrm{HOCH}^{\mathrm{N}}$. It serves as a case example of how to affiliate and coordinate actions to foster SD at HEIs. Funded by the German Ministry of Education and Research (BMBF), scientists from eleven German universities ${ }^{1}$ and multiple disciplines allied in order to accelerate SD as a topic of peer-learning and application (Bassen et al., 2017). The $\mathrm{HOCH}^{\mathrm{N}}$ collaboration is structured

\footnotetext{
${ }^{1}$ Collaboration partners in alphabetical order: Freie Universität Berlin, Universität Bremen, Technische Universität Dresden, Universität Duisburg-Essen, Hochschule für Nachhaltige Entwicklung Eberswalde, Universität Hamburg, Leuphana Universität Lüneburg, Ludwig-Maximilians-Universität München, Eberhard Karls Universität Tübingen, Universität Vechta, Hochschule Zittau-Görlitz
} 
along several fields of action, which all are of importance if a whole institution approach of SD (cf. UNESCO, 2014) is aimed for. These fields of action are: Governance; Research; Teaching and Education; Operations; Sustainability reporting; and Transfer/Outreach/Third Mission.

\subsection{Advances of implementing SD at German universities}

For each field of action, a guideline ${ }^{2}$ based on particular research results was created, outlining insights and measures of how to incorporate SD at an institutional level ${ }^{3}$. These guidelines are designed as an orientation pattern for universities that just started to implement SD measures. Moreover, a strong network for SD at universities was built during the first period of the project (2016-2018). Additional universities from all over Germany joined $\mathrm{HOCH}^{\mathrm{N}}$ and its endeavor to strengthen SD activities in all fields of action. A digital map was set up to visualize individual as well as institutional commitment to SD (see figure 1).

\footnotetext{
2 as beta-version; guidelines and further information on the $\mathrm{HOCH}^{\mathrm{N}}$ project available online at: www.hoch-n.org; to date, guidelines are available in German only, but English versions are in preparation.

${ }^{3}$ Because six different guidelines were created by several author teams and based on diverse research approaches, no details of methods or data are presented here; those can be tracked via publications that go beyond an introduction of the $\mathrm{HOCH}^{\mathrm{N}}$ collaboration as an entity - which this paper is meant to be - and that are listed at www.hoch-n.org.
} 


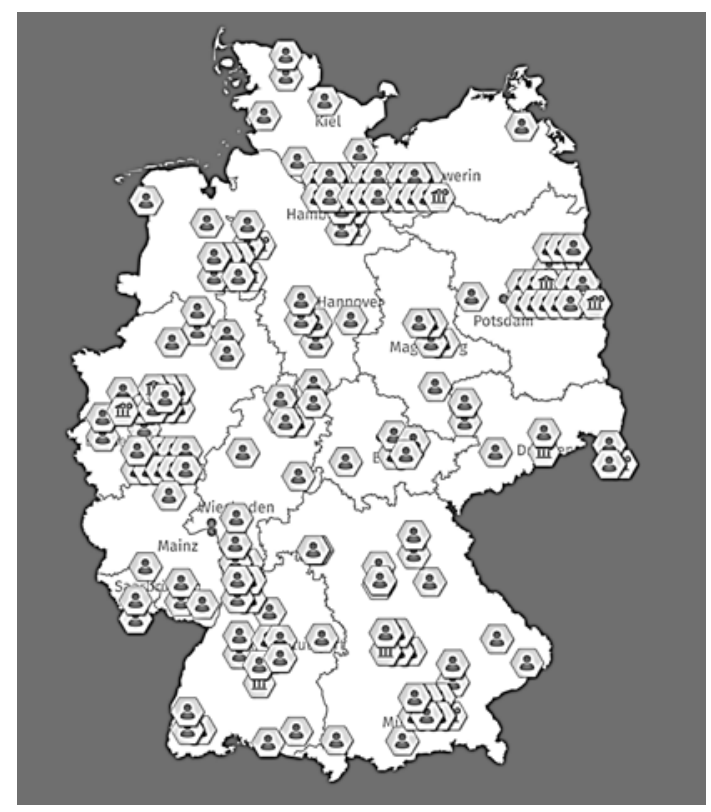

Figure 1. Digital HOCHN ${ }^{N}$ map of Germany, displaying individual and institutional SD initiatives. (Source: https://www.hochn.uni-hamburg.de/en/5-mitmachen.html). The online version provides detailed information on each of the initiatives listed. Initiatives apply for inclusion on the map via netzwerk@hoch-n.org.

Individuals from more than 110 German universities (approx. 1/4 of all German HEIs) are part of the $\mathrm{HOCH}^{\mathrm{N}}$ network by now, showing the continuously growing engagement for SD at universities. In Addition, the core partners of the $\mathrm{HOCH}^{\mathrm{N}}$ collaboration elaborated a shared understanding of the notion of SD at universities across various disciplines and institutions (Vogt et al., 2018). Going beyond a reductionist definition of SD, this shared commitment rather outlines different dimensions of transformation that have to be aligned in order to substantially change HEIs towards sustainability. Acknowledging a normative, ethical implication of SD that nevertheless should not impede academic autonomy is a crucial aspect of this shared understanding. Further aspects of it are recognizing the potentially conflicting nature of different SD targets and trying to address and cope with dilemmas (e.g. consider rebound effects and find ways to prevent them) as well as taking into account the exceptional responsibility that HEIs have not only in training and educating future generations but also as local, regional, national and global stakeholders.

To strengthen international networking on $\mathrm{SD}$ at universities, a $\mathrm{HOCH}^{\mathrm{N}}$ Sustainable Development Summit (HSDS, cf. www.hsds.uni-hamburg.de) was held in collaboration with COPERNICUS Alliance - a European network on ESD - as well as the European Postgraduate Symposium on SD, a casual union of researchers who refer to SD issues in their work. At HSDS, more than 200 participants form over 20 counties in Europe and beyond exchanged their knowledge, experiences and examples of how to foster SD-related 
projects and structures at universities. As $\mathrm{HOCH}^{\mathrm{N}}$ is an open network, it also aims at further international partners to associate with.

\subsection{Challenges of SD at universities (in Germany)}

The $\mathrm{HOCH}^{\mathrm{N}}$ network provides orientation patterns and peer-learning options for implementing SD measures at all fields of action and serves as a platform for exchange and collaboration. It contributes to advancing (applied) organizational development towards a sustainable future. Yet, many challenges arise when it comes to amplifying SD activities at universities. While not all of those challenges identified within the $\mathrm{HOCH}^{\mathrm{N}}$ consortium via peer discussion can be mentioned in detail here, some of the key challenges are:

- To establish and adhere to a whole institution approach as claimed by UNESCO (2014), i.e. to relate to all fields of (institutional) action and all stakeholders in a well-balanced and coherent way. Scattered initiatives and single projects for SD are relevant starting points, but (E)SD can only permeate organizational / university culture if it is systematically and comprehensively incorporated into the higher education system.

- To find ways of identifying and solving antagonistic effects of SD-related endeavors, such as conflicting impacts in terms of ecological and social dimensions of SD, for example. Within the science sector, the goal of internationalization on the one hand and reducing $\mathrm{CO}_{2}$ emissions due to travel on the other are a striking case of conflicting goals. Both targets are pertinent for universities in a globalized world and although digital tools allow for alternatives to travel, still new solutions and pathways of how to achieve one target without compromising the other have to be found and tested.

- To foster inter- and transdisciplinary research and collaboration, not as a substitute but as added value to conventional disciplinary work. Of course, this is bound to efforts and time resources which are usually very restricted anyway. Reinforcing teamwork across disciplinary and other boundaries still is necessary on a large scale to ensure transformation towards SD. This also is bound to the enhancement of new research profiles and identities, i.e. altered self-concepts of disciplines (from mono- to multi-disciplinary research identities).

- To enable new ways of learning, which not only means project-based learning and interactive teaching as modern forms of knowledge and skills acquisition. It also refers to different conceptions of learning and the way we are used to deal with problems and problem solving. Scharmer (2016), for example, outlines learning processes according to "Theory U” as sophisticated for SD and future-oriented leadership. This means to completely transcend conventional ideas of research, studying and education (cf. Bellina et al., 2018). 
Further challenges of SD at universities and especially of implementing ESD within tertiary education are discussed by Barth et al. (2016), for example. As emerging field of research and application, (E)SD at HEIs in the context of the global SDGs provides many different prospects. Progress of the $\mathrm{HOCH}^{\mathrm{N}}$ collaboration in addressing the mentioned challenges will be shared on the website www.hoch-n.org.

\section{Examples of ESD approaches: New perspectives for Higher Education}

Many different approaches of how to integrate ESD into tertiary education do exist (cf. Barth et al., 2016.), some focusing on special SD content (such as introducing the SDGs; detailed know-how concerning environmental protection, etc.), others focusing on didactic issues (such as project-based learning; living-labs; peer-learning, etc.). Building capacities in terms of knowledge and - even more essential - sustainability-related habits and skills is key in ESD. In order to illustrate advances and new perspectives for ESD at universities, three examples of approaches explored within the $\mathrm{HOCH}^{\mathrm{N}}$ context are specified. Of course, these selected examples are not exhaustive, neither for $\mathrm{HOCH}^{\mathrm{N}}$ nor for ESD in general. Yet, they bring in progressive models and methodologies for further discussion as well as evaluation.

\subsection{Creating shared visions via serious play techniques}

Research on team processes and performance shows that shared mental models are important for effectiveness and achievement (Mathieu et al., 2000). Thus, generating shared mental models and visions of how sustainable universities of the future might look like is a proper first step for achieving sustainability-related university development. In addition, Design Thinking as well as Serious Play are recent tools that help substantiate rather abstract notions. This is why Lego ${ }^{\circledR}$ Serious Play® (LSP) methodology is used as a means for teamwork on SD. In a series of workshops, LSP was introduced and applied in order to elaborate on shared visions. Some of the key elements referred to in different models and workshops were, for example: strong connections between universities and society; people from all status groups and disciplines cooperate; high-tech and green solutions are integrated at campus; awareness of SD is at the heart of each university.

\subsection{Enhance explorative learning via constellation techniques}

New ways of learning and problem solving in order to cope with the claims of global SD require not only an openness to new perspectives but also new methodologies and lines of (self-)reflection. Explorative and reflective attitudes can be trained by constellation techniques that are rooted in early ideas of sociometry and psychodrama (Moreno, 2001). Theories, models, hypotheses are visualized “on stage”, i.e. going beyond mere discussions, information and their dynamics (constellations) are put into action by persons. 
Constellation techniques are interactive methodologies that can help to generate new insights and interpretations of situations and patterns. Exploring possible ways of interaction between systemic elements via roleplay and/or "vicarious perception" can be used as powerful tools of experienced-based group learning. A detailed and comprehensive description of how constellation techniques are applied within research and teaching provide Müller-Christ and Pijetlovic (2018).

\subsection{Train integrated mindsets, e.g. "Five Minds for the Future"}

System thinking and integrated mindsets are crucial for tackling SD-related problems and for generating solutions of the grand challenges of the Anthropocene. Various theories and models do exist that describe key skills of future viability. One of those is the idea of the "Five Minds for the Future” by Gardner (2006). He thoroughly delineates five mindsets and virtues that are seen as essential for future education and vocational training. Whereas each of these mindsets is of relevance per se, their integrated training makes the difference for success. The five mindsets are:

1. The disciplined mind, including: deep understanding and experience of at least one field of profession; a mastery of different schools of thought; a motivation for lifelong learning.

2. The synthesizing mind, including: detecting parallels and patterns of concepts; being able to bridge gaps and to connect, to identify and use synergies, to bring thoughts, views and theories together.

3. The creating mind, including: ability to generate new ideas and solutions to problems, to transcend current standards and viewpoints; driven by curiosity and pioneering spirit.

4. The respectful mind, including: social skills such as empathy and active listening; communication competences in general, especially to communicate with others in a respectful and appreciative way; grant tolerance and benevolence to others; overcome prejudice.

5. The ethical mind, including: reflection and application of ethical principles; mature understanding of fairness, truthfulness, loyalty; adoption of (social) responsibility and critical self-reflection.

Special programs developed for fostering these "Five Minds for the Future" in an integrated way based on coaching methods (Schmitt, 2014) thus address SD-related skills. 


\section{Conclusion}

In this introductory paper, SD at HEIs was presented as a general topic and as a particular collaboration project of German universities $\left(\mathrm{HOCH}^{\mathrm{N}}\right)$. The $\mathrm{HOCH}^{\mathrm{N}}$ network is open to connect with further national and international partners in order to foster sustainabilityrelated organizational development and ESD at universities. Advances of the $\mathrm{HOCH}^{\mathrm{N}}$ initiative so far were summarized. Additionally, some key challenges of implementing SD at universities were noted: Referring to a whole institution approach; identifying and addressing antagonistic effects of SD; fostering inter- and transdisciplinary collaboration and new professional profiles for scientists; allowing and enabling new, unconventional ways of learning and endeavor. Focusing on ESD, the final section of this paper exemplified some methodologies and concepts used within the $\mathrm{HOCH}^{\mathrm{N}}$ context. With the case of $\mathrm{HOCH}^{\mathrm{N}}$ and the given examples, we hope to promote discussion about SD at universities as well as transformation within the sector of tertiary education. We hope to strengthen peer-learning on SD and to contribute to a professionalized research and application of SD at universities.

\section{References}

Barth, M., Michelsen, G., Rieckmann, M. \& Thomas, I. (Eds.) (2016). Routledge Handbook of Higher Education for Sustainable Development. London: Routledge.

Bassen, A., Schmitt, C. T. \& Stecker, C. (2017). Nachhaltigkeit an Hochschulen: entwickeln - vernetzen - berichten $\left(\mathrm{HOCH}^{\mathrm{N}}\right)$. [Sustainability at Higher Education Institutions: develop - network - report]. uwf UmweltWirtschaftsForum, 25, 139-146.

Bellina, L. , Tegeler, M., Müller-Christ, G. \& Potthast, T. (2018). Bildung für Nachhaltige Entwicklung at universities - $\mathrm{HOCH}^{N}$-Leitfaden [Education for Sustainable Development at universities - HOCH ${ }^{N}$-guideline]. https://www.hochn.uni-hamburg.de/downloads/handlungsfelder/lehre/hoch-n-leitfaden-bne-in-der-hochschullehre.pdf.

Gardner, H. (2006). Five Minds for the Future. Boston: Harvard Business School Press.

Hendry, J. (2014). Science and Sustainability: Learning from Indigenous Wisdom. New York, NY: Palgrave Macmillan.

Leal Filho, W., Shiel, C. \& Paço, A. (2016). Implementing and operationalizing integrative approaches to sustainability in higher education: the role of project-oriented learning. Journal of Cleaner Production, 133, 126-135.

Mathieu, J. E., Heffner, T. S., Goodwin, G. F., Salas, E. \& Cannon-Bowers, J. A. (2000). The Influence of Shared Mental Models on Team Process and Performance. Journal of Applied Psychology, 85 (2), 273-283.

Moreno, J. L. (2001). Psychodrama und Soziometrie. Essentielle Schriften (2. Aufl.) [Psychodrama and Sociometrics, 2nd Ed.]. Köln: Edition Humanistische Psychologie.

Müller-Christ, G. \& Pijetlovic, D. (2018). Komplexe Systeme lesen. Das Potenzial von Systemaufstellungen in Wissenschaft und Praxis. Berlin: SpringerGabler. 
Scharmer, C. O. (2016; 2007). Theory U: leading from the emerging future. A BK business book. San Francisco: Berrett-Koehler.

Schmitt, C. T. (2014). Mit kreativer Balance zu nachhaltiger Innovationsfähigkeit: Ein Coaching-Workshop zur Förderung Wertebasierter Flexibilität [Creative balance as basis for sustainable innovation capability-A coaching workshop to promote valuebased flexibility]. In B. Schültz, P. Strothmann, C. T. Schmitt \& L. Laux (Eds.), Innovationsorientierte Personalentwicklung: Konzepte, Methoden und Fallbeispiele für die Praxis (pp. 189-203). Wiesbaden: Springer-Gabler.

Steffen, W., Richardson, K., Rockström, J., Cornell, S. E. et al. (2015). Planetary boundaries: Guiding human development on a changing planet. Science, 347(6223), doi: 10.1126/science.1259855.

United Nations. (2015). Transforming our world: The 2030 agenda for sustainable development. https://sustainabledevelopment.un.org/sdgs

UNESCO. (2014). UNESCO roadmap for implementing the global action programme on education for sustainable development. https://sustainabledevelopment.un.org/.

Vogt, M., Lüdke-Spatz, L., Weber, C. et al. (2018). Nachhaltigkeitsverständnis des Verbundprojekts $\mathrm{HOCH}^{\mathrm{N}}$ [Shared notion of Sustainability within the $\mathrm{HOCH}^{\mathrm{N}}$ collaboration].https://www.hochn.uni-hamburg.de/-downloads/2018-09-04nachhaltigkeitsverstaendnis-hoch-n.pdf. 